\title{
Gene expression profile of human T cells following a single stimulation of peripheral blood mononuclear cells with anti-CD3 antibodies
}

Isabel Garcia Sousa ${ }^{1,2}$, Kelly Cristina Rodrigues Simi ${ }^{3}$, Manuela Maragno do Almo ${ }^{4}$, Maryani Andressa Gomes Bezerra ${ }^{3}$, Gero Doose ${ }^{5,6}$, Tainá Raiol ${ }^{7}$, Peter F. Stadler ${ }^{5,8,9}$, Steve Hoffmann ${ }^{5,10}$, Andréa Queiroz Maranhão ${ }^{1,2}$ and Marcelo Macedo Brigido ${ }^{1,2^{*}}$ (D)

\begin{abstract}
Background: Anti-CD3 immunotherapy was initially approved for clinical use for renal transplantation rejection prevention. Subsequently, new generations of anti-CD3 antibodies have entered clinical trials for a broader spectrum of therapeutic applications, including cancer and autoimmune diseases. Despite their extensive use, little is known about the exact mechanism of these molecules, except that they are able to activate T cells, inducing an overall immunoregulatory and tolerogenic behavior. To better understand the effects of anti-CD3 antibodies on human T cells, PBMCs were stimulated, and then, we performed RNA-seq assays of enriched T cells to assess changes in their gene expression profiles. In this study, three different anti-CD3 antibodies were used for the stimulation: two recombinant antibody fragments, namely, a humanized and a chimeric FvFc molecule, and the prototype mouse mAb OKT3.

Results: Gene Ontology categories and individual immunoregulatory markers were compared, suggesting a similarity in modulated gene sets, mainly those for immunoregulatory and inflammatory terms. Upregulation of interleukin receptors, such as IL2RA, IL1R, IL12RB2, IL18R1, IL21R and IL23R, and of inhibitory molecules, such as FOXP3, CTLA4, TNFRSF18, LAG3 and PDCD1, were also observed, suggesting an inhibitory and exhausted phenotype.

Conclusions: We used a deep transcriptome sequencing method for comparing three anti-CD3 antibodies in terms of Gene Ontology enrichment and immunological marker expression. The present data showed that both recombinant antibodies induced a compatible expression profile, suggesting that they might be candidates for a closer evaluation with respect to their therapeutic value. Moreover, the proposed methodology is amenable to be more generally applied for molecular comparison of cell receptor dependent antibody therapy.
\end{abstract}

Keywords: Anti-CD3, RNA-seq, Antibody therapy, Regulatory T cells, Antibody engineering

\footnotetext{
* Correspondence: brigido@unb.br

${ }^{1}$ Department of Cell Biology, Institute of Biological Sciences, University of Brasilia, Brasilia, Brazil

${ }^{2}$ Instituto de Investigação em Imunologia, Instituto Nacional de Ciências e

Tecnologia (iii-INCT), Brasilia, Brazil

Full list of author information is available at the end of the article
}

(c) The Author(s). 2019 Open Access This article is distributed under the terms of the Creative Commons Attribution 4.0 International License (http://creativecommons.org/licenses/by/4.0/), which permits unrestricted use, distribution, and reproduction in any medium, provided you give appropriate credit to the original author(s) and the source, provide a link to the Creative Commons license, and indicate if changes were made. The Creative Commons Public Domain Dedication waiver (http://creativecommons.org/publicdomain/zero/1.0/) applies to the data made available in this article, unless otherwise stated. 


\section{Background}

Immunosuppressive therapies based on monoclonal antibodies (mAbs) started in the 1980s, with the use of Muromonab-CD3 (OKT3), an antihuman CD3 antibody, for attaining long-term graft survival after organ transplantation [1]. After decades of use, this biopharmaceutical was withdrawn from clinics due to its toxic side effects [2]. However, the emergence of a new generation of (re)engineered recombinant antibodies has sparked hopes that anti-CD3 antibodies may again be used to induce peripheral tolerance [3], renewing the enthusiasm for CD3-targeted therapies. Hence, anti-CD3 therapy is now being tested for several autoimmune and inflammatory diseases $[4,5]$. Furthermore, recent clinical data on the use of Teplizumab in type I diabetes [6] contribute to this optimism that new anti-CD3 therapies for autoimmunity and transplantation will become available in a foreseeable time. The administration of anti-CD3 antibodies induces the general activation of $\mathrm{T}$ cells, which may lead to a state of tolerance not yet fully understood $[3,7]$. The proposed mechanism of a peripheral tolerance induction rests upon a potential modulation of regulatory lineages of the CD4 phenotype [8,9], even though CD8 regulatory cells were also shown to be affected $[10,11]$. Peripherally induced regulatory cells control the activation of $\mathrm{T}$ cells, promoting negative feedback in the inflammatory response. The induction of a more regulatory environment by anti-CD3 antibodies could produce antigen-specific tolerance and alleviate the immune response. More recent data on human clinical data suggest that other mechanisms such as $\mathrm{T}$ cell exhaustion $[11,12]$ or the induction of inhibitory receptors on T cells $[13,14]$ could also contribute to the suppression of the immune response.

The effect of anti-CD3 therapy has been addressed in different studies trying to elucidate its mechanism by assessing the genetic profile of $\mathrm{T}$ cells induced by those antibodies. These studies have been performed by microarray analysis [15-17] or, more recently, by Next Generation Sequencing (NGS) [18, 19]. Nevertheless, in the majority of the investigations, anti-CD3 is not the unique stimulus but is combined with anti-CD28 antibody and/or interleukins, such as IL2. More importantly, these studies are often performed using isolated $\mathrm{T}$ cells and thus are in a very different context from the PBMC environment. In the present work, we compared two recombinant antibody fragments, a chimeric fragment and a humanized fragment in an FvFc format, with their prototypic antibody OKT3. The treatment was performed using healthy human donor PBMCs in vitro. The global changes in the transcriptome profile were assessed using RNA-seq. Subsequently, their T cell differentiation markers and immunoregulatory signatures were compared. Our data showed that, despite the antibody format, the three anti-CD3 antibodies induced a common pattern of gene expression strongly enriching regulatory genes as well as genes involved in inhibitory signaling. We propose that these comparative analyses could be exploited as a validation tool in designing new and more effective CD3-binding molecules.

\section{Results}

Global change in the gene expression profile in human T cells induced by anti-CD3 treatments

To compare the effects of each of the three anti-CD3 antibodies on human $\mathrm{T}$ cells, the gene expression profiles were analyzed. T cells were obtained from 72-h untreated or treated PBMCs with one of the three antiCD3 antibodies: OKT3, FvFc M (OKT3 scFv fused to human IgG1 Fc), and a humanized version of this $\mathrm{FvFc}$ (FvFc R). Anti-CD3 was used as the sole stimulus. To avoid any further stimulation, $T$ cells were obtained by negative selection, using magnetic beads for cell surface markers. The purity of the $\mathrm{T}$ cell population was assessed by flow cytometry and was above 96\% (Additional file 1: Figure S1). The transcriptomes of stimulated and unstimulated $\mathrm{T}$ cells from a single individual were obtained by performing sequencing in two replicates. More than 55 million paired-end reads of $150 \mathrm{bp}$ length were obtained. The reads were mapped to the human reference genome (hg19); of the total reads, 84 to 94\% were mapped (Table 1 ).

Subsequently, we assessed differentially expressed genes (DEGs) by comparing each anti-CD3 antibodytreated sample with the control of unstimulated $\mathrm{T}$ cells. The gene sets found to be differentially expressed in the different treatments are shown as a MA plot in Fig. 1a and as a Venn diagram in Fig. 1b. OKT3 treatment resulted in a larger set of differentially expressed genes (7089) with a fold change of less than -0.8 or above 0.8 , followed by FvFc R treatment with 2425 DEG and FvFc $M$ treatment with 1406 DEG. We found 860 genes that were equally regulated among the treatments, considering a padj $\leq 0.05$. Except for FvFc $R$ treatment, DEGs were mostly downregulated. FvFc $\mathrm{R}$ induced the most

Table 1 Read mapping rates and statistics for RNA-seq data

\begin{tabular}{llll}
\hline Replicate & All Reads & Mapped Reads & \% Mapped Reads \\
\hline Unstimulated (1) & 59623760 & 54990450 & 92 \\
Unstimulated (2) & 61444968 & 58149032 & 94 \\
FvFc R (1) & 57712398 & 54065899 & 93 \\
FvFc R (2) & 54633094 & 51012088 & 93 \\
FvFc M (1) & 62274364 & 58117856 & 93 \\
FvFc M (2) & 65142278 & 60452698 & 92 \\
OKT3 (1) & 60724236 & 51446623 & 84 \\
OKT3 (2) & 59435924 & 50336034 & 84 \\
\hline
\end{tabular}




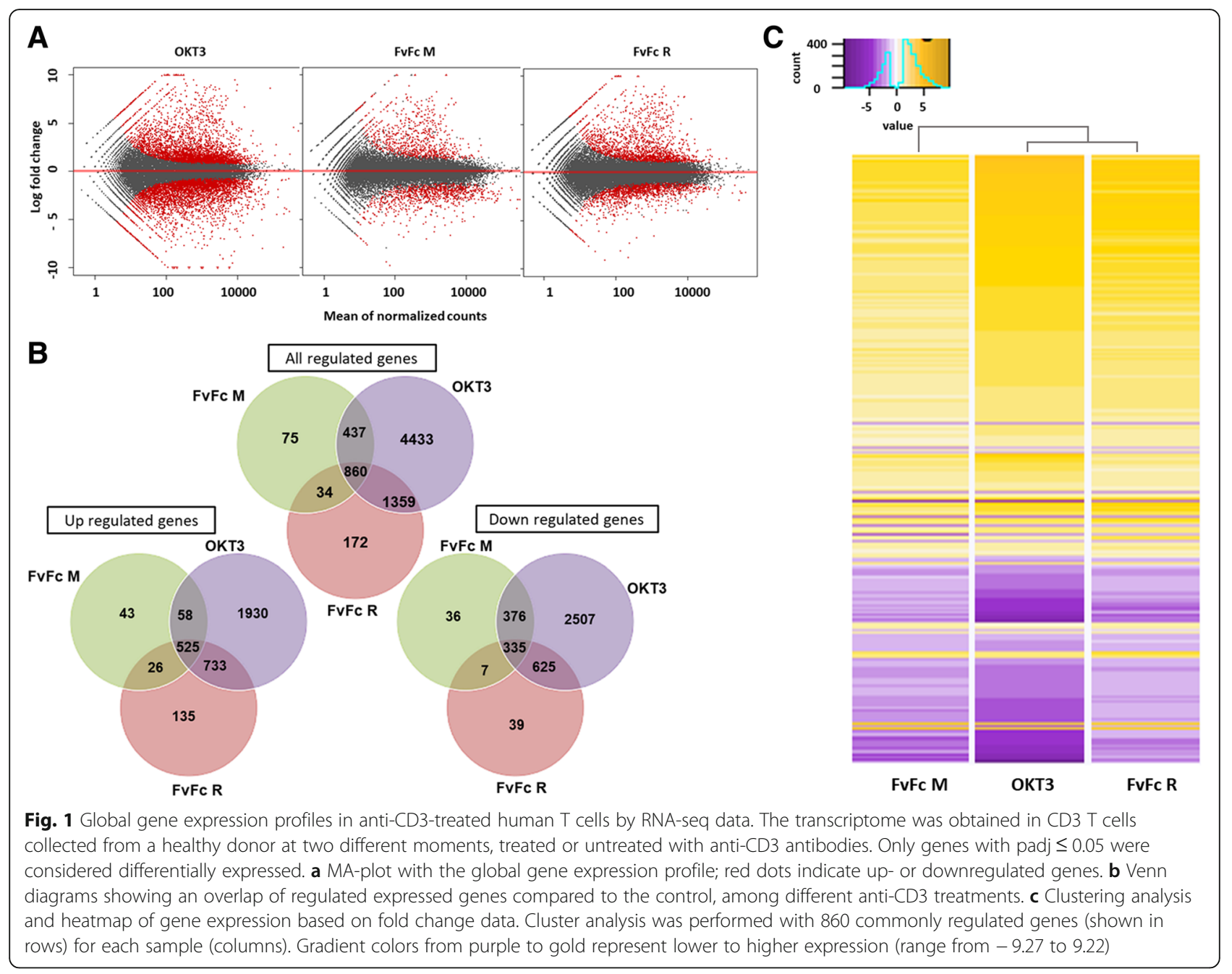

unbalanced DEG dataset, with 58\% (1,419) upregulated over $41 \%(1,006)$ downregulated DEGs. The gene regulation profile promoted by $\mathrm{FvFc} R$ was more similar to OKT3 than FvFc M, even though the cluster analysis suggested a similar DEG profile for each treatment (Fig. 1c).

\section{Associations of DEGs with gene ontology categories}

Anti-CD3 stimulation was shown to affect different set of genes $[18,19]$. Therefore, functional characterization of the differentially expressed genes was performed using GO term enrichment analysis. Anti-CD3 activated and repressed DEGs were separately classified for the GO category "biological process". Upregulated genes were dominated by terms associated with cell proliferation (Fig. 2), reflecting the anti-CD3 associated activation of $\mathrm{T}$ cells. To visualize changes in GO term enrichment and coverage (completeness), immune-associated terms were selected among up- and downregulated DEGs for each antibody treatment, focusing on those associated with the immune response and inflammation typically associated with anti-CD3 therapy (Fig. 3).

All antibodies induced a similar profile of GO term enrichment, coverage and FDR adjusted $p$ value, shown by radar plots (Fig. 3). Among the upregulated genes, the predominance of OKT3-induced GO term coverage was less obvious. Between selected terms, the most enriched GO term among the upregulated genes was the Regulation of Regulatory $\mathrm{T}$ Cell Differentiation (GO:0045589), but terms for the regulation of IFN $\gamma$ (GO:0032729), IL-10 (GO: 0032653) and IL-12 production (GO:0032655) were also highlighted.

The downregulated DEG set enriched terms reflected categories that fade after antibody treatment. It is notable that, among the GO terms enriched by genes repressed after treatment, the term "regulation of inflammatory response" (GO:0050727), was the most conspicuous. Furthermore, the terms "immune response-regulating signaling pathway" (GO:0002433) and 

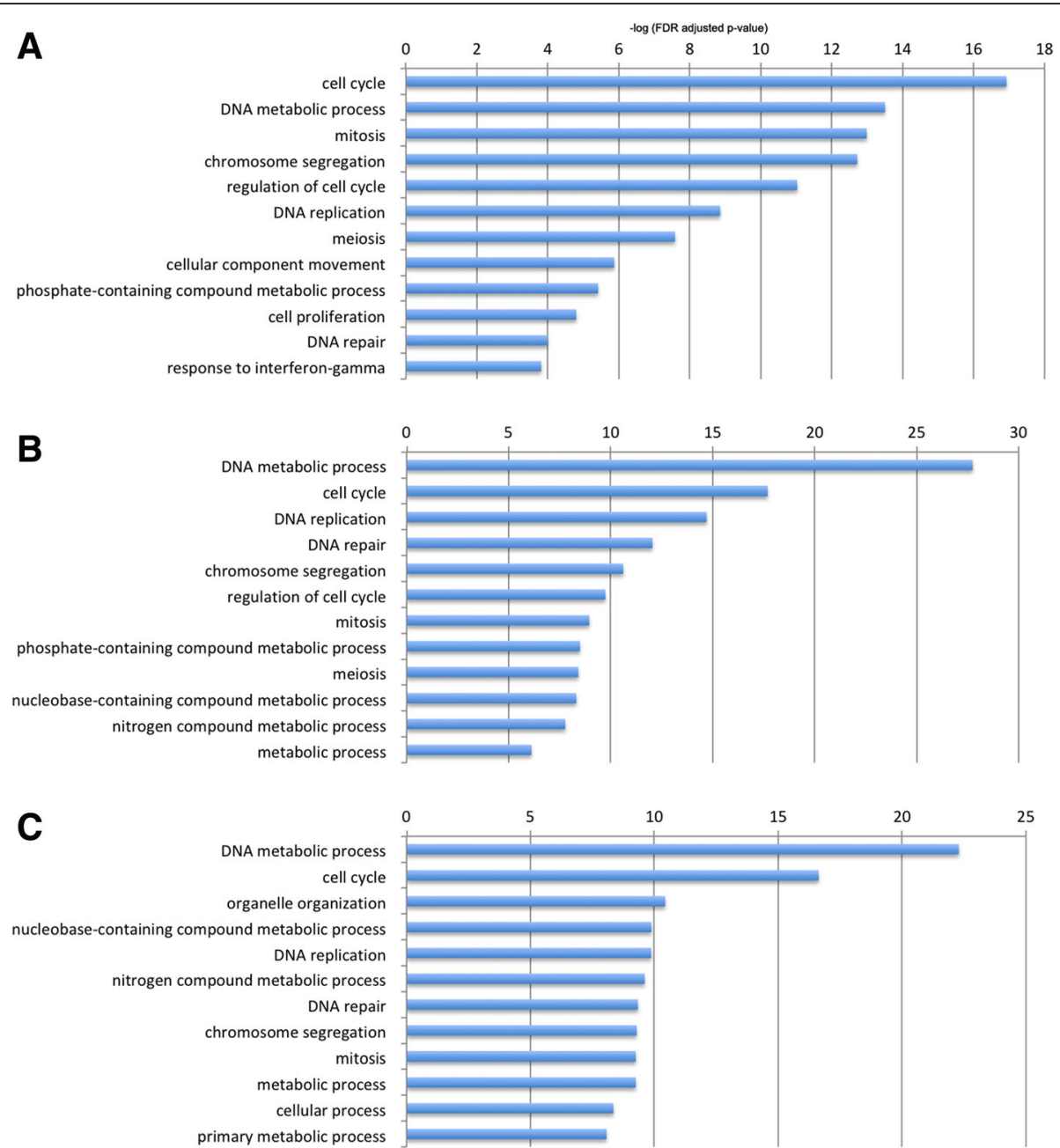

Fig. 2 Gene set enrichment analysis of differentially expressed genes. Gene ontologies associated with upregulated genes in peripheral blood CD3 cells following anti-CD3 treatment. The top twelve enriched biological process categories were calculated using Panther. GO terms associated with cell proliferation was found to be overrepresented. a FvFc M-treated, (b) FvFc R-treated, and (c) OKT3-treated T cells

"activation of immune response" (GO:0002253) were also evident (Fig. 3).

\section{Regulation of cytokines and their receptors by anti-CD3 stimulation}

Anti-CD3 antibody therapy is strongly associated with an over secretion of cytokines, also known as a "Cytokine Storm" [4]. The deleterious consequences of the cytokine production are assumed to be promoted by the Fc part of the molecule, and novel humanized antibodies can circumvent these consequences by inducing a nonmitogenic effect. Our data suggest that the in vitro administration of all three anti-CD3 antibodies induce the upregulation of several cytokine genes, including INFG, IL17A, IL17F, LIF and TNF (Fig. 4). However, when we analyzed the expression of IL17 in human donors by RT-qPCR, we noticed that even though the IL17A gene expression was consistently expressed along all treatments in the NGS panel, its induction was variable among antibody-treated donor T cells (Fig. 5a). The FvFc $\mathrm{R}$ and OKT3 treatment also induced upregulation of IL6 and IL32. OKT3 treatment induced additional interleukins such as IL1B, IL2, IL3, IL9, IL13, IL12B, IL21 and IL22 (Fig. 4).

Cytokine receptors were also induced after antibody treatment, including strong upregulation of the IL2 receptor subunit genes, IL2RA and IL2RB (Fig. 4). IL2RA expression was also tested in the qPCR panel of treated donor $\mathrm{T}$ cells, suggesting that any form of anti-CD3 induces the expression of the IL2 receptor $\alpha$-chain, also known as CD25 (Fig. 5b). Moreover, all antibody treatments induced the expression of IL1R2, IL12RB2, IL18R1, IL21R, IL23R (Figs. 4 and 5c). However, as suggested by the NGS panel, anti-CD3treated $\mathrm{T}$ cells increased their sensitivity toward IL1, IL2, IL12, IL18, IL21 and IL23. 


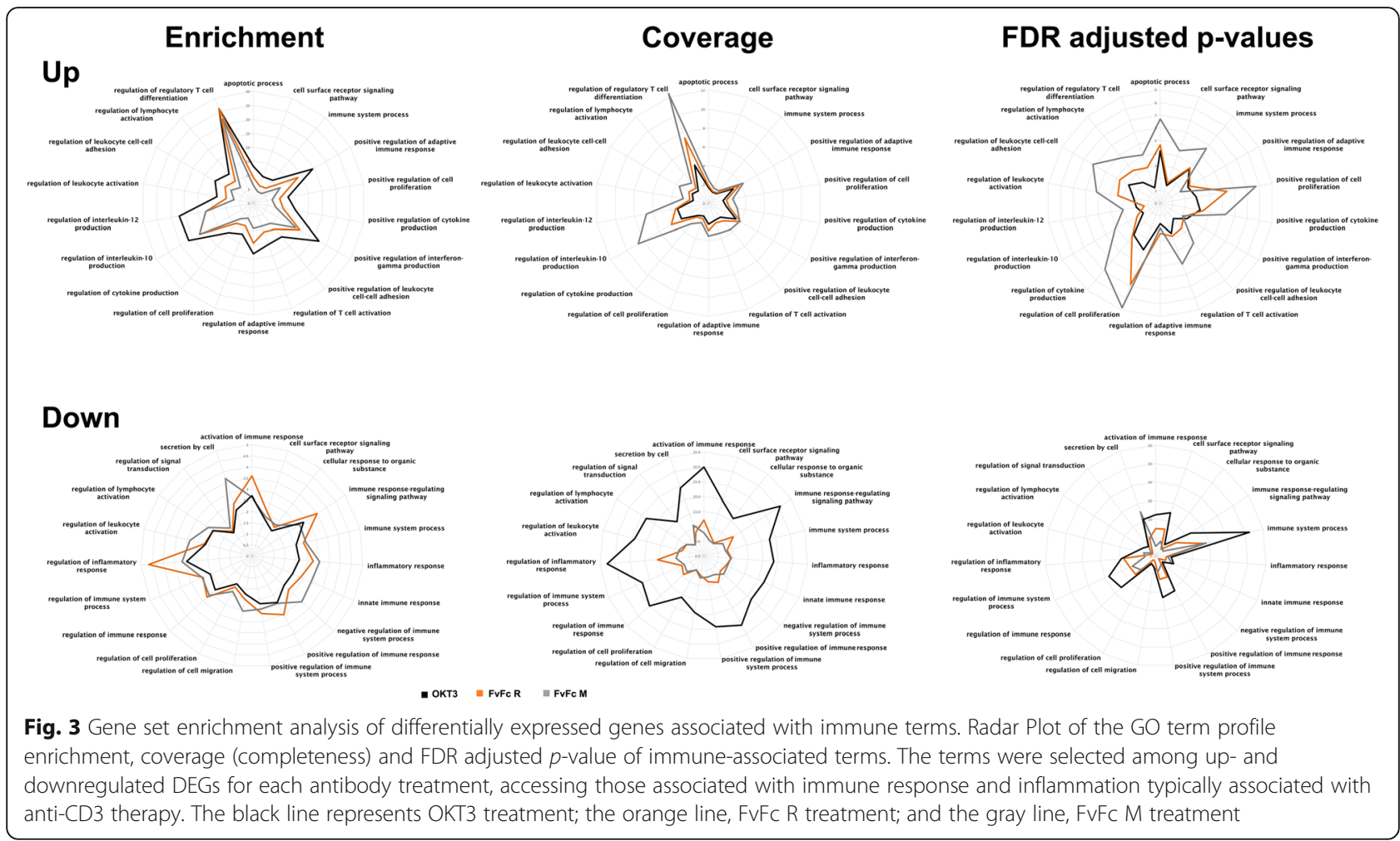

Anti-CD3 antibody treatment induced the upregulation of several interleukin and interleukin receptors genes, but only a few interleukins and receptors were downregulated due to antibody treatment. IL10 and IL24 expression was significantly repressed after OKT3 and FvFc R treatment, while IL18BP was repressed by OKT3 and FvFc M. In addition, OKT3 treatment also reduced the expression of IL18 (Fig. 4). IL10 was further investigated by qPCR. Notwithstanding, the qPCR panel suggested that OKT3 treatment had a variable effect on IL10 expression among treated donor cells, and the FvFc-based antibody had no significant effect (Fig. 5d).

Downregulation of interleukin receptors makes $\mathrm{T}$ cells less sensitive to their cognate cytokine. The NGS panel suggested that OKT3 treatment might interfere with signaling of interleukins IL10, IL11 and IL13, due to the downregulation of IL10RA, IL10RB, IL11RA and IL13RA1 (Fig. 4). IL6R was downregulated after treatment with OKT3 and FvFc R. The IL17RA codes for IL17A specific receptor and was found to be downregulated after OKT3 treatment, with a barely significant qvalue (0.0069); nevertheless, the GPCR panel confirmed this tendency for downregulation after treatment with any of the antibodies (Fig. 5e). The IL17RC gene, which codes for a receptor for both IL17A and IL17F, was found to be downregulated after both OKT3 and FvFc $M$ treatment. The receptor for IL7, IL7R, was shown to be downregulated with both $\mathrm{FvFc} R$ and OKT3 treatment. The qPCR panel corroborated these results, suggesting that most donor $\mathrm{T}$ cells respond to any antiCD3 antibody format, reducing the IL7R expression levels (Fig. 5f).

Anti-CD3 stimulation regulates phenotypic marker genes Activation of resting $\mathrm{T}$ cells by anti-CD3 antibodies can induce cell differentiation, and indeed, several phenotypic markers are modulated after antibody treatment. Resting $\mathrm{T}$ cells can differentiate in several lineages of effector and regulatory phenotypes, and specific genetic markers can characterize these $\mathrm{T}$ cell phenotypes. We compared several markers for CD4 and CD8 subpopulations depicted as panels to visualize their possible differentiation (Fig. 6). To confirm prototype marker expression levels found in the NGS panel, qPCR analyses were performed using anti-CD3 treated T cells (Fig. 7). Some expression markers are key for charactering $\mathrm{T}$ cell subpopulations. The Th1 marker TBX21, which codes for the TBET transcription factor, was shown to be significantly induced only with OKT3 treatment in the NGS panel (Fig. 4). The qPCR panel corroborated the NGS data (Fig. 7a), suggesting a minimal effect of FvFc antibodies on TBX21 expression. STAT4, another Th1 marker, was also only induced by OKT3 in the NGS experiment, but qPCR data suggests that FvFc R could also affect the expression levels of STAT4 in stimulated cells [20, 21] (Figs. 4 and 7b). GATA3, a Th2 phenotypic 


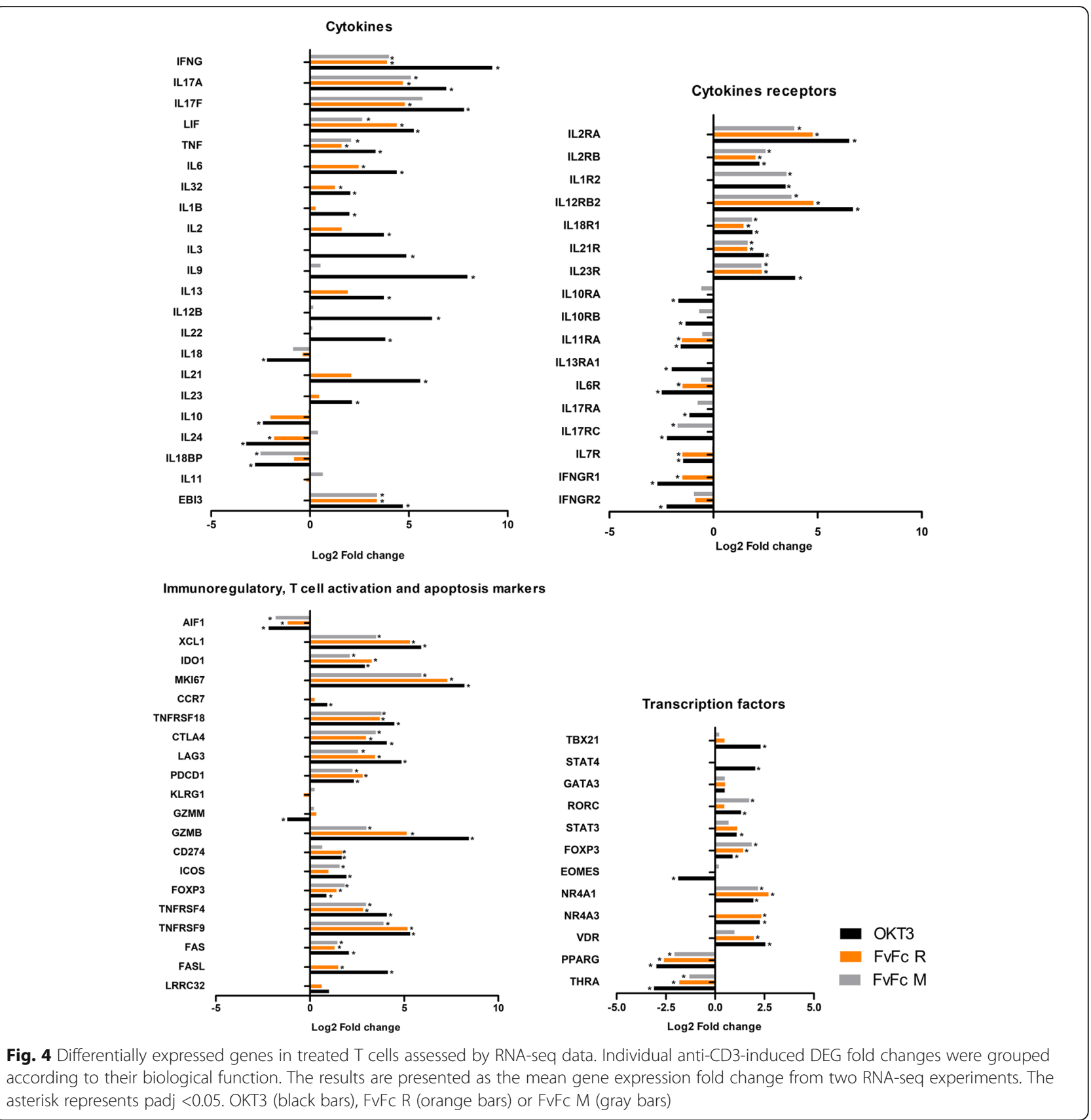

marker, was not significantly induced in NGS or qPCR data (Figs. 4 and 7c). However, other characteristic markers of this subtype were induced [21, 22] (Fig. 6).

In addition, we also analyzed markers for the Th17 subpopulation [23, 24] (Figs. 4, 5, 6 and 7). The gene that codes for ROR $\mathrm{R}_{\mathrm{T}}$, RORC was found to be slightly upregulated after treatment with both OKT3 and FvFc $\mathrm{M}$ antibodies (Fig. 4), but without significance (padj > 0.01). In the qPCR panel, RORC was shown to be barely activated in all three treatments (Fig. 7d). IL17A, known to be produced by Th17 cells, was upregulated in the NGS panel, but these data were not supported by qPCR, which suggests a variable and mild regulation of this gene (Fig. 5a). The third marker, STAT3, was found to be induced by OKT3 in the NGS data and was induced by OKT3 and FvFc R treatments, as measured by qPCR (Fig. 7e). Interestingly, the FvFc M antibody induced a very contrasting effect on different donors. Half of the donors showed an upregulated profile, while the other half showed a downregulated profile.

$\mathrm{T}$ cells can assume a regulatory phenotype, and many regulatory markers were found in this analysis $[25,26]$ (Fig. 6). FOXP3, a major transcription factor that is associated with the human $\mathrm{T}$ regulatory phenotype, was 


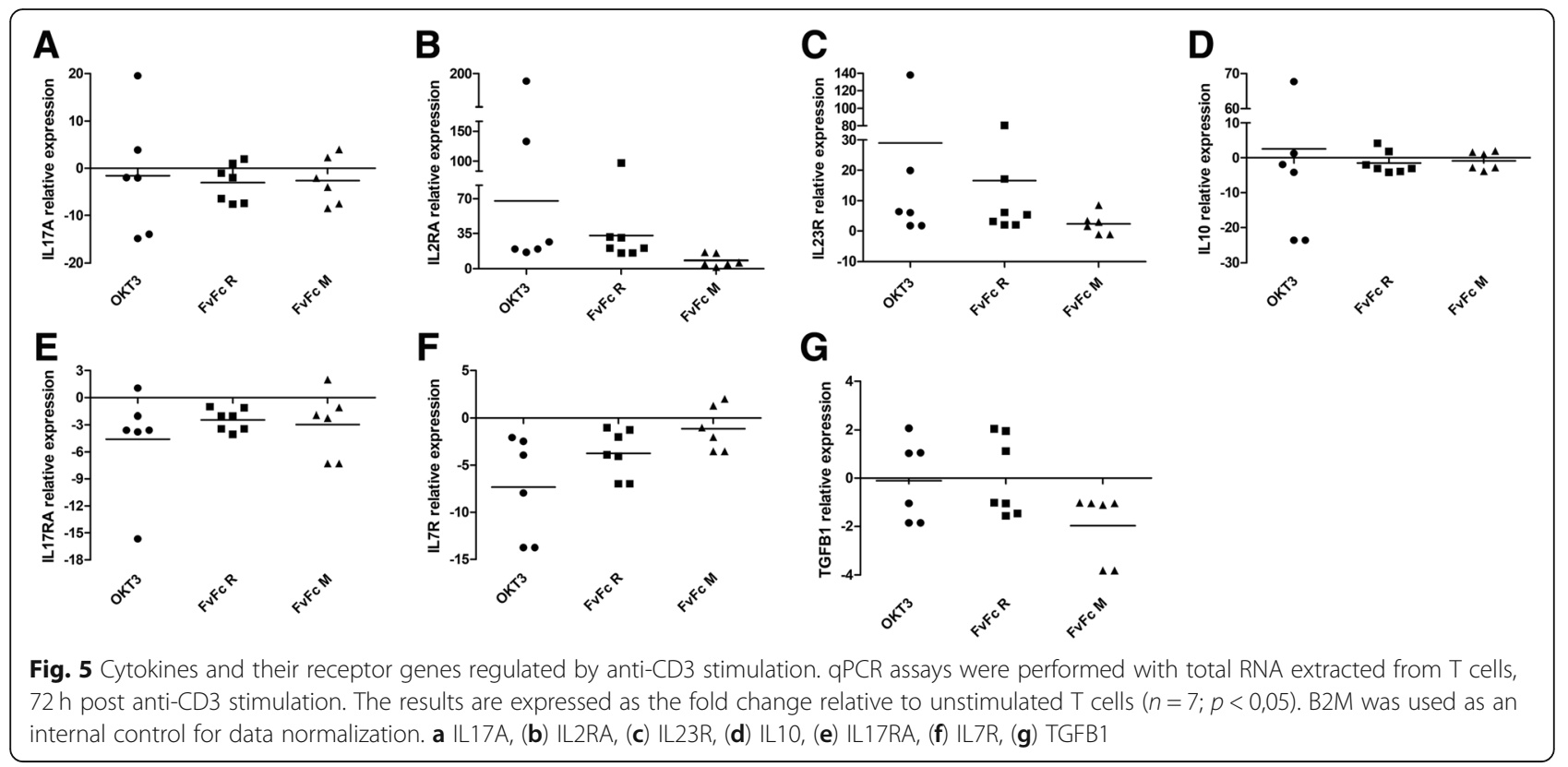

upregulated in the NGS data for all antibody treatments. These data were corroborated by qPCR (Fig. 7f). GITR (TNFRSF18) was strongly upregulated by all antibodies (approximately 16-fold, Fig. 4), and this effect was also observed for all donors in qPCR (Fig. 7g). CTLA4 and LAG3 were similarly upregulated in the NGS (Fig. 4), and qPCR data supported this finding (Fig. $7 \mathrm{~h}$ and i), but the effect was less pronounced for FvFc antibodies compared to OKT3. The gene that codes for PD-1, namely, PDCD1, was also consistently induced by all antibody treatments (approximately 5-fold, Fig. 4), and qPCR data confirmed this observation (Fig. 7j).

Modulations of CD8 T cell markers were also observed after anti-CD3 treatment, suggesting changes in the CD8 T cell population [27, 28] (Fig. 6). Among these markers, EOMES and KLRG1 were repressed after all the antiCD3 treatments, but GMZB was strongly induced by anti-CD3. These three markers were also tested by qPCR, which confirmed the tendency of the NGS data (Fig. $7 \mathrm{k}, 1$ and $\mathrm{m}$ ). Moreover, markers of regulatory CD8 $T$ cell [29], such as IL2RA, were sharply induced by OKT3 and FvFc R but to a lesser extent by FvFc M. CD274 (PD-L1) was only marginally induced in all treatments (Fig. 6), and FOXP3 showed a variable profile (Fig. 7f). ICOS was weakly induced only by OKT3 and FvFc M (Fig. 4).

Phenotypic markers associated with $\mathrm{T}$ cell activation, cell death and apoptosis pathways were also affected by anti-CD3 treatment. Figure 4 resumes the induction/repression of these markers after anti-CD3 treatment. Overall, OKT3 induced most activation markers except EOMES and AIF1, while FvFc-based antibodies had a milder profile. Among the activation molecules, IFGN,
GZMB, IL2RA, TNFRSF4 and TNFRSF9 showed remarkable induction. Cell death was the fate of activated cells, and the FAS/FASLG pathway was induced after T cell activation. The anti-CD3 effect on FAS induction was slight (Fig. 6) and variable among donors (Fig. 7n), and FASLG was very consistent among donors with the treatment of FvFc R (Fig. 7o). GITR, along with PDCD1, was consistently induced by all the treatments (Figs. 4, 6, $7 \mathrm{~g}$ and $\mathrm{j})$.

\section{Anti-CD3 stimulation modulates genes that encode nuclear receptor transcription factors}

Nuclear receptors integrate a family of transcription factors that respond to hormones and hydrophobic molecules that have been associated with the control of the immune response [30]. Thus, the PFAM family for $\mathrm{Nu}$ clear Receptor (PF00104), was used to probe antibodyinduced DEGs. Anti-CD3 treatment induced the expression of PF00104-associated genes. OKT3 induced 7 genes, while FvFc $R$ induced 3 and FvFc $M$ induced 2 genes. The orphan nuclear receptor gene NR4A1 was activated in all treatments at a padj $<10^{-5}$. Three other PF00104 annotated genes were found in two of three treatments: NR4A3, RORC, and VDR (Fig. 4). NR4A3 codes for a mitogen-associated nuclear receptor (http:// www.uniprot.org/uniprot/Q92570). RORC is mentioned above as a marker for lymphocyte lineages. VDR codes for the vitamin D3 receptor, and its overexpression was detected in all antibody treatments by qPCR (Fig. 7p).

Among the downregulated DEGs, peroxisome proliferator-activated receptor gamma (PPARG), a gene associated with the development of Tregs, was found to be 4- to 9-fold less expressed than that in the unstimulated 


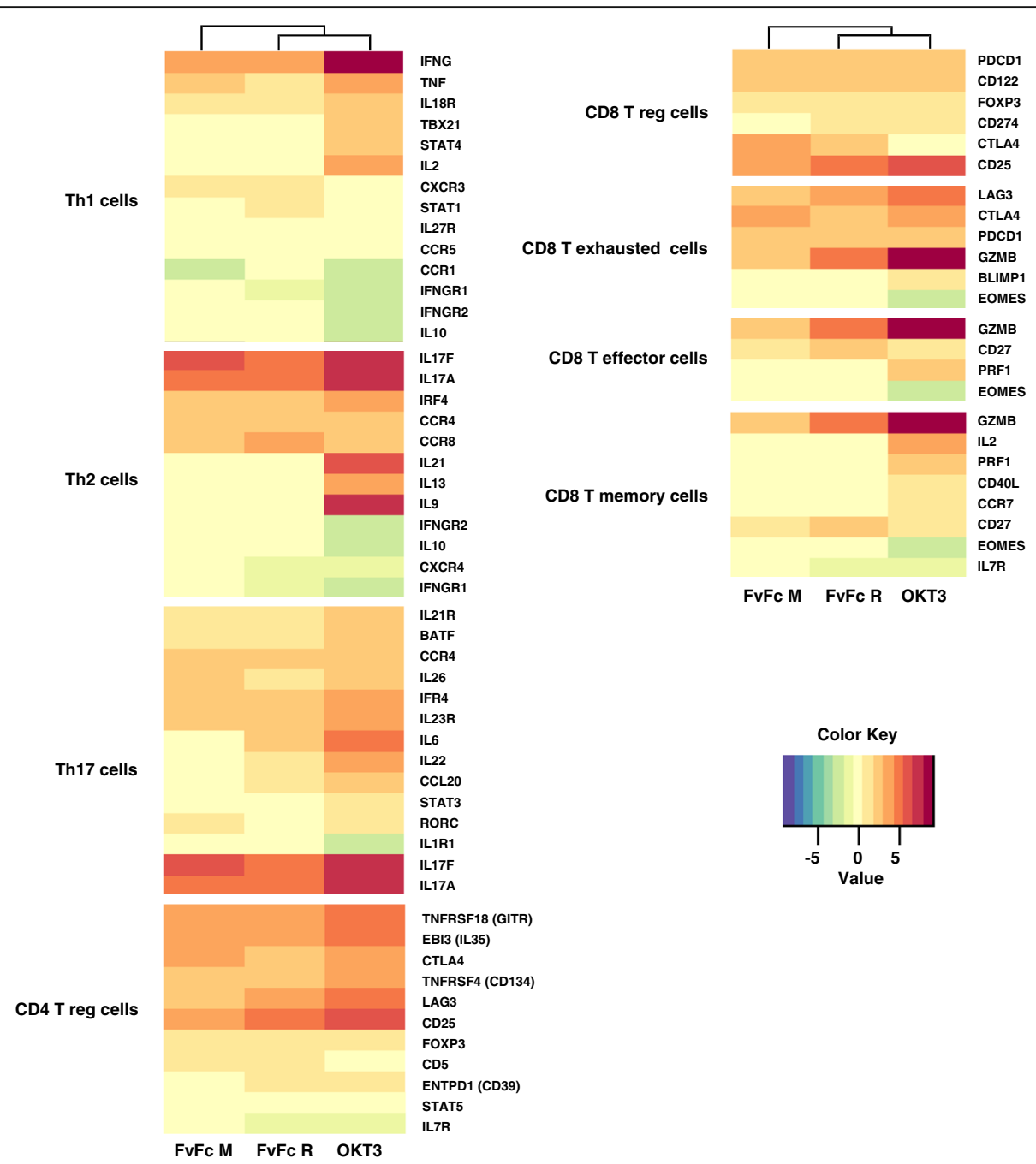

Fig. $6 \mathrm{~T}$ cell subpopulation signatures. Cluster analysis based on the fold change data of regulated genes (shown in rows) for each sample (columns) and grouped into T cell populations. Only genes with padj $\leq 0.05$ were considered differentially expressed. Gradient colors from blue to dark brown represent lower to higher expression (range from -2.69 to 9.22)

T cells (Fig. 4). Moreover, the THRA gene that codes for thyroid hormone receptor alpha was also repressed in all treatments.

\section{Effect of an exclusive anti-CD3 stimulation}

To compare the global gene expression profile under the effect of anti-CD3 antibodies with that of activated $\mathrm{T}$ cells, we paralleled our results with those described by Zhao and colleagues (2014), who probed DEGs of immortalized $\mathrm{T}$ cells cultured in the presence of anti-CD3 and anti-CD28 antibodies. Their DEG dataset after $72 \mathrm{~h}$ treatment was compared with NGS data generated in the present work focusing on DEGs regulated after antiCD3 treatment without the costimulatory anti-CD28 stimulus. Among the 12 most opposite DEG (Additional file 1: Table S3), three genes were selected for qPCR analysis: AIF1, XCL1 and IDO1 (Fig. 7q, r and s). XCL1 and
IDO1 were induced by all of the anti-CD3 treatments, as observed in the qPCR panel, while AIF1 was found to be repressed after anti-CD3 treatment.

\section{Discussion}

Anti-CD3 antibodies are known to induce immunosuppression and have been proposed for several therapies, including those for different autoimmune diseases and acute transplanted organ rejection. For approximately two decades, Muromonab-CD3 (OKT3) therapy was used as an adjuvant for acute episodes of graft rejection, but its use was discontinued due to pronounced side effects [2]. However, despite the prolonged clinical use, the mechanism of action of OKT3 is still uncertain. In this study, human $\mathrm{T}$ cells were treated with anti-CD3 antibodies in vitro, within the complexity of the PBMC milieu, in an attempt to simulate the natural ambiance 


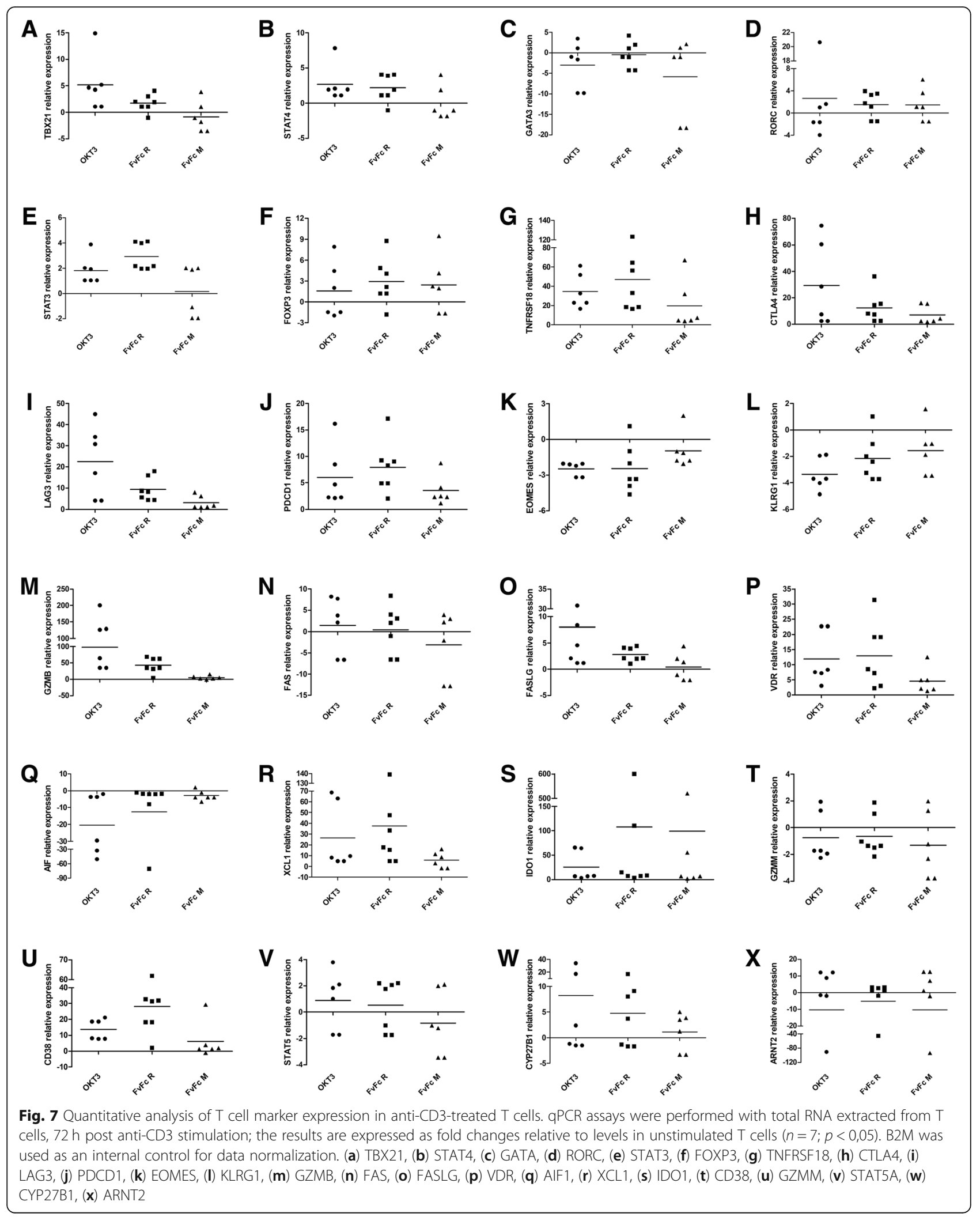


that occurs in the intravenous administration of therapeutic anti-CD3. This in vitro experimental model was used to compare the mouse mAb OKT3 with two recombinant antibody fragments inspired by the mAb: a humanized and a chimeric human IgG1 in the FvFc format (scFv-hinge- $\mathrm{CH} 2-\mathrm{CH} 3$ ).

Currently, most antibody therapies rely on full-sized mAbs, derived from chimeric, humanized or fully human sequences, but new molecular formats may represent technological and economical alternatives. The FvFc format used here represents a novel solution as a singlechained homodimeric molecule that mimics heteromultimeric mAbs [31-36]. The DEG profiles induced by each antibody format were very similar as judged from the enrichment analysis, despite the larger DEG set induced by OKT3, especially for the repressed DEG set. The ontology-based classification for up- and downregulated DEGs suggests that all antibody formats induce a very similar profile, marked by a sharp mitotic response (with a low $p$-value), and a higher, even significant, $\mathrm{p}$ value for "Immune"-related GO. It is noteworthy that FvFc compares positively for several terms, such as regulation of "regulatory $\mathrm{T}$ cell" and "interleukin-10 production" and "inflammatory response." Overall, despite the larger set of OKT3 DEGs, FvFc molecules could enrich GO terms at least similarly.

The broader coverage of GO terms of OKT3 DEGs may reflect their greater mitogenic stimulus [31], while the humanized FvFc displayed a skewed DEG profile, yet preserving its function. Further analyses suggest that the chimeric molecule FvFc $\mathrm{R}$ reproduces the OKT3 DEG profile more accurately than $\mathrm{FvFc} \mathrm{M}$, despite the better binding proprieties of the latter molecule. Therefore, the humanization process seems to have preserved the original OKT3 paratope in the recombinant molecules, suggesting them as alternative CD3 binders for clinical anti-CD3 therapy.

The mitogenic activity of OKT3 and other anti-CD3 antibodies renders them especially investigated for therapeutics [37-40]. The analysis of differentially expressed gene ontology classification suggests that all three antiCD3 antibodies modulate a distinct number of genes related to cell proliferation and mitosis. This supports a significant impact of anti-CD3 therapy on T cell proliferation as observed for the proliferation marker MKI67 and the T-specific activation marker CD25 (IL2RA). The activation of T cells by OKT3 and other anti-CD3 antibodies is usually associated with the clinical efficacy of this antibody [39]. However, upregulation of activation markers does not correlate with antibody mitogenic activity, since non mitogenic anti-CD3 antibodies may also induce activation markers in vivo [40]. Therefore, these data corroborate a previous characterization of the $\mathrm{FvFc}$ $\mathrm{R}$ antibody, shown to be less mitogenic than OKT3 [31], despite inducing several activation markers, as observed in the present study.

Most models for anti-CD3 therapy rely on CD4 regulatory cells [41-43], but the majority of data supporting it came from mouse models. Recent data on humanized antibodies in clinical trials highlight the role of CD8 cells in tolerance associated with anti-CD3 therapy, suggesting a two-phase model: a short-term depletion of $\mathrm{T}$ cells followed by induction of regulatory mechanisms [6]. A burst of cell activation initially induces mitotic mechanisms. Our data suggest that even after 3 days of antiCD3 stimulation, activated T cell DEGs are still dominated by a mitotic signature, as seen by GO term enrichment, but, along with, barely detected emerging immunoregulatory mechanisms.

Several regulatory phenotypes have been proposed, along with genes usually associated with a regulatory function [44]. For CD4 cells, regulatory cells are distinguished from effector cells that are classified as Th1, Th2, and Th17. A TBET signature with high production of IFNY characterizes Th1 cells, but TBX21, which codes for TBET, is only weakly upregulated by OKT3, in line with previous observations [43]. Th2 cells do not appear to be induced by anti-CD3 since no significant alteration in GATA3 expression was observed. Beyond that, markers for Th17 and T regulatory cells are predominantly found in anti-CD3-treated cells. Among those with the Th17 phenotype, IL17A, IL17F, and IL16 were upregulated, and FOXP3, GITR, LAG3, and CTLA4 were characteristic of the regulatory phenotype. These markers were all observed to some degree in each of treatments but commonly were weakly expressed among donors stimulated with FvFc M.

The anti-CD3 treatment seemed to bias toward a Th17/Treg polarity, as suggested before $[45,46]$. However, FOXP3, an important marker of regulatory cells, was only weakly induced after PBMC stimulation. It is possible that by analyzing gene expression after $72 \mathrm{~h}$ of anti-CD3 induction, we missed the transient FOXP3 peak kinetics $[18,19]$. Moreover, the activation of IRF4, a late effect of FOXP3 activation, represses FOXP3 and may negatively affect its expression [47]. IRF4 was upregulated in all the anti-CD3-treated cells. Interestingly, anti-CD3-treated cells showed an apparent decrease in the mRNA levels of CD127 (IL7R), the IL-7 receptor, for which downregulation is considered to be a hallmark of a bona fide regulatory phenotype in humans $[29,48,49]$.

IL10 is a marker for regulatory CD8 and the CD4 (Tr1) phenotype [50, 51]. We found no significant IL10 regulation except for a slight decline due to treatment with OKT3. However, we noted an enrichment of the "regulation of Interleukin-10" GO term, suggesting that the machinery for IL10 production was activated in antiCD3-treated cells. FvFc $\mathrm{R}$ antibody was previously 
shown to induce a high IL10/IFN $\gamma$ ratio compared to OKT3 in anti-CD3-stimulated PBMCs [31], although no significant induction of IL10 was observed in the present study. Nevertheless, the increase in the IL10/IFN $\gamma$ ratio observed by Silva and colleagues could be explained in part by a more consistent induction of the IFNG gene in OKT3-treated T cells, or likewise due to a non-lymphocytic origin of the produced IL10 probed in the whole PBMCs [31].

Clinical data on novel humanized antibodies suggest new mechanisms of anti-CD3 action in humans. In mice, studies have suggested that anti-CD3 therapy induces immunosuppression dependent on CD4 $\mathrm{T}$ cells, with stimulated helper cells developing a regulatory phenotype. However, in humans, the CD8 lineage also seems to contribute to the tolerogenic effect of anti-CD3, either by inducing differentiation into CD8 regulatory cells [15, 29] or by leading CD8 $\mathrm{T}$ cells to exhaustion [11, 12]. Data from Teplizumab clinical trials suggested that the immunosuppressive effect of the humanized antibody is due to anergic and exhausted CD8 cells [12, 52], along with CD8 and CD4 Tregs [15]. Nonetheless, inhibitory receptors were clearly activated in our model system, including PDCD1, CTLA4, and LAG3, suggesting that inhibition of the immune response and inflammation after $72 \mathrm{~h}$ of a proliferative stimulus might have led to an exhausted phenotype [14]. Otherwise, inhibitory receptors may not indicate exhaustion, but a detuning of CD8 $\mathrm{T}$ activation. It is possible that these inhibitory receptors signify the transition from a highly activated $\mathrm{T}$ cell state toward a differentiation/memory profile [11, 53]. The high and consistent induction of the PDCD1 gene (PD1) observed here suggests a general detuning of antiCD3-treated cells, that may underlie the basis of antiCD3 therapeutic effects.

The detuning of $\mathrm{T}$ cell following PD-1 expression may contribute to the effect of anti-CD3, but other molecular players may also contribute to immunosuppression. IDO1 is a tryptophan catabolic enzyme known to induce regulatory $\mathrm{T}$ cells and immunosuppression $[54,55]$. Although usually produced by monocytes, a CD4+IDO+ lymphocyte population had been characterized [56]. Anti-CD3 treatment induced IDO1 upregulation in T cells, although not uniformly among donors. In this sense, a putative IDO-producing $\mathrm{T}$ cell could trigger a profound regulatory effect by locally restricting available tryptophan. This finding may represent an alternative mechanism of T-cell-induced immunosuppression that could be therapeutically exploited.

\section{Conclusions}

Novel therapeutic anti-CD3 antibodies development could focus on regulatory associated GO term enrichment and specific subpopulation markers. The in vitro assay proposed here, based on a simple and economical procedure, seems to be efficient to compare novel antibody molecules before clinical evaluation. Development of new antibodies or novel pharmaceutical association could benefit from this in vitro methodology, allowing a novel discovery pipeline based on a System Biology approach.

In conclusion, we used a deep transcriptome sequencing method for comparing three anti-CD3 antibodies regarding Gene Ontology enrichment and immunological marker expression. The present data showed that both recombinant antibodies induced a compatible expression profile, suggesting that they might be candidates for closer evaluation concerning their therapeutic value. Moreover, the proposed methodology is amenable to be more generally applied for molecular comparison purposes.

\section{Methods}

\section{Donors}

Peripheral blood was collected from seven healthy individuals enrolled in this study (Additional file 1: Table S1). For NGS a single donor was analyzed and for qPCR assays, seven healthy individuals were enrolled. All human blood experiments were performed in accordance to the Ethics Committee of the University of Brasilia guidelines, which approved the study protocol (CAAE: 32874614.4.0000.0030). A written informed consent was obtained from all human donors.

\section{Antibodies}

OKT3 was purchased from eBioscience (San Diego, CA, USA). The humanized antibody fragment FvFc $R$ is a single-chain $\mathrm{FvFc}$ molecule and was previously described (FvFc version R) [31]. The chimeric FvFc M contains the original OKT3 $\mathrm{VH}$ and $\mathrm{VL}$ coding sequences fused to human IgG1 Fc and cloned in the pMIRES expression vector. The FvFc antibody fragments were affinity purified from supernatants of CHO-K1 transfected cells.

\section{PBMC stimulation and $\mathrm{T}$ cell preparation}

Fresh PBMCs were isolated using Ficoll-Paque density gradient centrifugation (GE Healthcare, Uppsala, Sweden). PBMCs were cultured in RPMI media (Invitrogen, Carlsbad, CA, USA) supplemented with $4 \mathrm{mML}$ glutamine and 10\% FBS in the presence or absence of soluble anti-CD3 antibodies. A total of $250 \mathrm{ng}$ of antibody was applied to $1 \times 10$ [6] PBMC/mL. T cells were isolated after $72 \mathrm{~h}$ of PBMC treatment, using magnetic beads by negative selection (according to the manufacturer's instructions). Briefly, PBMCs were selectively depleted of CD16, CD19, CD20 cells and were discarded (Dynabeads ${ }^{\oplus}$ Untouched $^{\text {TM }}$ Human $\mathrm{T}$ 
Cells Kit, Invitrogen, Carlsbad, CA, USA). The purity of $\mathrm{T}$ cell enrichment was checked using flow cytometry (Additional file 1: Figure S1).

\section{RNA extraction}

Total RNA was extracted from $\mathrm{T}$ cells isolated after PBMC stimulation using the miRNeasy ${ }^{\circ}$ Mini Kit (Qiagen, Valencia, CA, USA) as described before [46]. RNA integrity and purity were evaluated using a Bioanalyzer 2100 (Agilent Technologies Genomics, Santa Clara, CA, USA). All RNA samples used in this work showed an RIN $>7$.

\section{Sample sequencing and differential gene expression analysis}

RNA-seq was performed by Macrogen, Inc. (Seoul, Korea), using the Illumina $\mathrm{HiSeq}^{\mathrm{Tm}} 2500$ platform (Illumina, San Diego, CA, USA) according to the manufacturer's standard protocol. The total RNA, up to $1500 \mathrm{ng}$, was sent in a RNA-stable tube (Biomatrica, Inc., San Diego, CA) to preserve the integrity of the RNA, and Illumina sequencing was performed in a $2 \times 150 \mathrm{nt}$ paired-end mode. All sequencing reads produced by Illumina were analyzed for quality control using FASTQC [57]. The reads were aligned to the human genome GRCh37/hg19 downloaded from the UCSC Genome Browser [58] using open source Segemehl, version 0.2.0 [59] with the split read option -S. The aligned files were ordered and indexed using Samtools [60] followed by read counts using HTSeq-count [61]. For a differential gene expression analysis, the reads of CD3 T cell treated and untreated samples uniquely aligned by Segemehl were used. To identify differentially expressed genes (DEGs) for each treatment comparison (treated versus untreated), two replicates per condition were analyzed using the Bioconductor package DESeq2 [62] applying a significance threshold for the adjusted $p$-values of 0.05 .

\section{Analysis of gene functions}

The enrichment GO terms for biological processes of DEG were also assessed. For this purpose, upregulated $\left(\log _{2} \mathrm{FC}>1.2\right)$ and downregulated $\left(\log _{2} \mathrm{FC}<1.2\right)$ gene set enrichment analyses were performed using functional categories of the database Gene Ontology (GO). The Panther software $[63,64]$ was used to calculate enrichment, p-values and FDR adjusted p-values. The super category "biological process" was used, and within this category, GO terms related to the immune system and inflammatory process were further investigated.

Nuclear receptor analysis was performed exclusively for the Pfam family PF00104 of the Pfam database (http://pfam.xfam.org/). Members of PF00104 were searched in the DEG set using regular expression and analyzed individually.

\section{Gene expression analysis by qPCR assays}

Quantitative PCR was performed as previous described [46]. Briefly, total RNA isolated from T cells was utilized for cDNA synthesis using an $\mathrm{RT}^{2}$ First Strand Kit (Qiagen, Valencia, CA, USA). The expression genes were quantified using $\mathrm{RT}^{2}$ qPCR SYBR Green/ROX MasterMix (Qiagen, Valencia, CA, USA) following the manufacturer's instructions. The housekeeping gene B2M was used as the endogenous control. qPCR assays were performed using an ABI Step One Plus Real-Time PCR System (Applied Biosystems, Austin, Texas, EUA) and the $2^{-\Delta \Delta C t}$ method was used to calculate mRNA transcript levels (fold change) using $\mathrm{RT}^{2}$ Profiler PCR Array Data Analysis software (SABiosciences, Frederick, MD, USA for analysis. Three independent experiments were performed in triplicate.

\section{Statistical analysis}

All RNA-seq experiments statistical evaluations were performed using Bioconductor package DESeq2 [62] based in Benjamini-Hochberg method for adjusted pvalues. Gene function attribution was performed using adjusted p-values calculated by the Binomial statistic and Mann-Whitney U Test (Wilcoxon Rank-Sum Test) by Panther software [63, 64]. Real Time qPCR p-values were calculated based on Student's t-test using $\mathrm{RT}^{2}$ Profiler PCR Array Data Analysis software.

\section{Additional file}

\begin{abstract}
Additional file 1: Table S1 Donors information. Figure S1 Analysis of the purity of T cell enrichment. After the enrichment of T cells, the sample was incubated with antibody anti-CD18 FITC, anti-CD3 APC and anti-CD4 PE. A) graphical representation of the physical characteristics of the cells determined by dispersion, B) expression of the CD18 molecule, C) expression of the CD3 molecule within the CD18 population. Figure S2 Recombinant FvFc forms compete with OKT3 antibody for binding to the CD3 surface molecules on human PBMCs. Lymphocytes were gated in a forward versus side scatter dot plot, and the binding of the anti-human CD3 antibodies was plotted as a histogram. The decreased median fluorescence intensity reflects the inhibition of the FITC conjugated OKT3. Table S2 Inhibition of OKT3 binding to CD3 molecules in human PBMCs by FvFc forms. Figure S3 Principal component analysis of RNA-seq reads. Table S3 Data from DEG for $72 \mathrm{~h}$ treatment of Jurkat cell with anti-CD3 and anti-CD28 was obtained from Zhao et al. (2014), supplementartay data, and compared with data for each anti-CD3 treated human T cell for the current work. (PDF 759 kb)
\end{abstract}

\section{Abbreviations}

DEGs: Differentially Expressed Genes; FvFc: antibody format - scFv fused to human IgG1 FC; NGS: Next Generation Sequencing; PBMC: Peripheral Blood Mononuclear Cells; qPCR: Quantitative Real Time PCR

\section{Acknowledgements}

We are thankful of CAPES and CNPq for scholarship funding and to FAPDF for financial support of this project.

\section{Authors' contributions}

IGS, KCRS, MMB and AQM designed the experiments. IGS, KCRS and MAGB processed the blood samples, performed cell culture for recombinant antibodies production and made flow cytometry. IGS, KCRS, GD, TR, MMB. 
and $\mathrm{SH}$ designed and performed all bioinformatics analysis. IGS and MMA conducted qPCR experiments. IGS, MMA, AQM and MMB wrote the manuscript. AQM, MMB, SH and PS contributed to the interpretation of the results and corrected and improved the paper. All authors read and approved the final version of the manuscript.

\section{Funding}

Research work was supported by FAP-DF (grant number: 193.000.560/2009). This study was financed in part by the Coordenação de Aperfeiçoamento de Pessoal de Nível Superior - Brasil (CAPES) - Finance Code 001. Brazilian Council for Research (CNPq) contributes with fellowship. The funding agencies, CAPES, CNPq and FAP-DF were not involved in the design of the study, collection, analysis, and interpretation of data and in writing the manuscript.

\section{Availability of data and materials}

RNA-Seq datasets are available at GEO (http://www.ncbi.nlm.nih.gov/geo) under the accession number GSE112899.

Supplementary informations are in Additional file.pdf.

\section{Ethics approval and consent to participate}

All human blood experiments were performed in accordance to the Ethics Committee of the University of Brasilia guidelines, which approved the study protocol (CAAE: 32874614.4.0000.0030). A written informed consent was obtained from all human donors.

\section{Consent for publication}

Not applicable.

\section{Competing interests}

The authors declare that they have no competing interests.

\section{Author details}

${ }^{1}$ Department of Cell Biology, Institute of Biological Sciences, University of Brasilia, Brasilia, Brazil. ${ }^{2}$ nnstituto de Investigação em Imunologia, Instituto Nacional de Ciências e Tecnologia (iii-INCT), Brasilia, Brazil. ${ }^{3}$ Molecular Biology Graduation Program, Institute of Biological Sciences, University of Brasilia, Brasilia, Brazil. ${ }^{4}$ Molecular Pathology Graduation Program, Medicine Faculty, University of Brasilia, Brasilia, Brazil. ${ }^{5}$ Bioinformatics Group, Department of Computer Science and Interdisciplinary Center of Bioinformatics, University of Leipzig, Leipzig, Germany. ${ }^{6}$ Interdisciplinary Center for Bioinformatics, University of Leipzig, Leipzig, Germany. ${ }^{7}$ Fiocruz Brasilia, Oswaldo Cruz Foundation (GEREB/Fiocruz), Brasilia, Brazil. ${ }^{8}$ Max-Planck-Institute for Mathematics in the Sciences, Leipzig, Germany. ${ }^{9}$ Santa Fe Institute, Santa Fe, NM, USA. ${ }^{10}$ Computational Biology Group, Leibniz Institute on Ageing - Fritz Lipmann Institute (FLI) and Friedrich-Schiller-University Jena, Jena, Germany.

Received: 29 April 2019 Accepted: 11 July 2019

Published online: 19 July 2019

\section{References}

1. Cosimi AB, Urton B, Colvin RB, Goldstein G, Laquaglia MP, Tolkoff-Rubin N, et al. Treatment of acute renal allograft rejection with OKT3 monoclonal antibody. Transplantation. 1981;32(6):535-9.

2. Reichert JM. Marketed therapeutic antibodies compendium. MAbs. 2012; 4(3):413-5.

3. Chatenoud L, Primo J, Bach JF. CD3 antibody-induced dominant self tolerance in overtly diabetic NOD mice. J Immunol. 1997;158(6):2947-54.

4. Chatenoud L, Bluestone JA. CD3-specific antibodies: a portal to the treatment of autoimmunity. Nat Rev Immunol. 2007;7(8):622-32.

5. Utset TO, Auger JA, Peace D, Zivin RA, Xu D, Jolliffe L, et al. Modified antiCD3 therapy in psoriatic arthritis: a phase I/II clinical trial. J Rheumatol. 2002; 29(9):1907-13.

6. Daifotis AG, Koenig S, Chatenoud L, Herold KC. Anti-CD3 clinical trials in type 1 diabetes mellitus. Clin Immunol. 2013;149(3):268-78.

7. You S, Zuber J, Kuhn C, Baas M, Valette F, Sauvaget V, et al. Induction of allograft tolerance by monoclonal CD3 antibodies : a matter of timing. Am J Transl Res. 2012;12(11):2909-19.

8. Belghith M, Bluestone JA, Barriot S, Mégret J, Bach JF, Chatenoud L. TGF- $\beta$ dependent mechanisms mediate restoration of self-tolerance induced by antibodies to CD3 in overt autoimmune diabetes. Nat Med. 2003;9(9):1202-8.
9. Gandhi R, Farez MF, Wang Y, Kozoriz D, Quintana FJ, Weiner HL. Cutting edge: human latency-associated peptide+ $T$ cells: a novel regulatory $T$ cell subset. J Immunol. 2010;184(9):4620-4.

10. Bisikirska B, Colgan J, Luban J, Bluestone JA, Herold KC. TCR stimulation with modified anti-CD3 mAb expands CD8+ T cell population and induces CD8+ CD25+ Tregs. J Clin Invest. 2005;115(10):2904-13.

11. Legat A, Speiser DE, Pircher H, Zehn D, Fuertes Marraco SA. Inhibitory receptor expression depends more dominantly on differentiation and activation than "exhaustion" of human CD8 T cells. Front Immunol. 2013; 4(DEC):1-15.

12. Long SA, Thorpe J, DeBerg HA, Gersuk V, Eddy JA, Harris KM, et al. Partial exhaustion of CD8 T cells and clinical response to teplizumab in new-onset type 1 diabetes. Sci Immunol. 2016;1(5):7793-802.

13. Horwitz DA, Pan S, Ou JN, Wang J, Chen M, Gray JD, et al. Therapeutic polyclonal human CD8+ CD25+ Fox3+ TNFR2+ PD-L1+ regulatory cells induced ex-vivo. Clin Immunol. 2013;149(PB):450-463.

14. Wallberg M, Recino A, Phillips J, Howie D, Vienne M, Paluch C, et al. AntiCD3 treatment up-regulates programmed cell death protein-1 expression on activated effector $T$ cells and severely impairs their inflammatory capacity. Immunology. 2017;151(2):248-60.

15. Ablamunits $V$, Bisikirska $B$, Herold KC. Acquisition of regulatory function by human CD8+ T cells treated with anti-CD3 antibody requires TNF. Eur J Immunol. 2010;40(10):2891-901.

16. Hamalainen $H$, Zhou H, Chou W, Hashizume H, Heller R, Lahesmaa R. Distinct gene expression profiles of human type 1 and type $2 \mathrm{~T}$ helper cells. Genome Biol. 2001;2(7):RESEARCH0022.

17. Hess K, Yang Y, Golech S, Sharov A, Becker KG, Weng NP. Kinetic assessment of general gene expression changes during human naive CD4+ T cell activation. Int Immunol. 2004;16(12):1711-21.

18. Birzele F, Fauti T, Stahl H, Lenter MC, Simon E, Knebel D, et al. Nextgeneration insights into regulatory $T$ cells: expression profiling and FoxP3 occupancy in human. Nucleic Acids Res. 2011;39(18):7946-60.

19. Zhao S, Fung-Leung WP, Bittner A, Ngo K, Liu X. Comparison of RNA-Seq and microarray in transcriptome profiling of activated T cells. PLoS One. 2014;9(1):e78644.

20. Weber C, Weber KSC, Klier C, Gu S, Wank R, Horuk R, et al. Specialized roles of the chemokine receptors CCR1 and CCR5 in the recruitment of monocytes and T H 1-like / CD45RO + T cells specialized roles of the chemokine receptors CCR1 and CCR5 in the recruitment of monocytes and T H 1-like / CD45RO \& T cells. Blood. 2011;97(4):1144-6.

21. Biedermann $\mathrm{T}$, Rocken M, Carballido JM. TH1 and TH2 lymphocyte development and regulation of $\mathrm{TH}$ cell-mediated immune responses of the skin. J Investig Dermatol Symp Proc. 2004;9(1):5-14.

22. Wurster AL, Rodgers VL, Satoskar AR, Whitters MJ, Young DA, Collins M, et al. Interleukin 21 is a T helper (Th) cell 2 cytokine that specifically inhibits the differentiation of naive Th cells into interferon $\gamma$-producing Th1 cells. J Exp Med. 2002;196(7):969-77.

23. Maddur MS, Miossec P, Kaveri SV, Bayry J. Th17 cells: biology, pathogenesis of autoimmune and inflammatory diseases, and therapeutic strategies. Am J Pathol. 2012;181(1):8-18.

24. Schraml BU, Hildner K, Ise W, Lee W, Whitney A, Solomon B, et al. The AP-1 transcription factor Batf controls TH 17 differentiation. Nature. 2009; 460(7253):405-9.

25. Josefowicz SZ, Lu L-F, Rudensky AY. Regulatory T cells: mechanisms of differentiation and function. Annu Rev Immunol. 2012;30(1):531-64

26. Chen X, Oppenhein JJ. Resolving the identity myth: key markers of functional CD4+FOXP3+ regulatory T cells. Int Immunopharmacol. 2011; 11(10):1489-96.

27. Mahnke YD, Brodie TM, Sallusto F, Roederer M, Lugli E. The who's who of Tcell differentiation: human memory T-cell subsets. Eur J Immunol. 2013; 43(11):2797-809

28. Liu J, Chen D, Nie GD, Dai Z. CD8+CD122+ T-cells: a newly emerging regulator with central memory cell phenotypes. Front Immunol. 2015; 6(October):6-11.

29. Churlaud G, Pitoiset F, Jebbawi F, Lorenzon R, Bellier B, Rosenzwajg M, et al. Human and mouse CD8+CD25+FOXP3+ regulatory $T$ cells at steady state and during Interleukin-2 therapy. Front Immunol. 2015;6(April):2-11.

30. Park BV, Pan F. The role of nuclear receptors in regulation of Th17/Treg biology and its implications for diseases. Cell Mol Immunol. 2015;12(5):533-42.

31. Silva HM, Vieira PMMM, Costa PLN, Pimentel BMS, Moro AM, Kalil J, et al. Novel humanized anti-CD3 antibodies induce a predominantly 
immunoregulatory profile in human peripheral blood mononuclear cells. Immunol Lett. 2009;125(2):129-36.

32. Shu L, Qi CF, Schlom J, Kashmiri SV. Secretion of a single-gene-encoded immunoglobulin from myeloma cells. Proc Natl Acad Sci U S A. 1993;90(17): 7995-9

33. Vaz De Andrade E, Freitas SM, Ventura MM, Maranhão AQ, Brigido MM. Thermodynamic basis for antibody binding to Z-DNA: comparison of a monoclonal antibody and its recombinant derivatives. Biochim Biophys Acta - Gen Subj. 2005;1726(3):293-301.

34. Secchiero P, Sblattero DI, Chiaruttinf C, Melloni E, Macor P, Zorzet S, et al. Selection and characterization of a novel agonistic human recombinant anti-trail-r2 minibody with anti-leukemic activity Department ofMorphology and Embryology, University ofFerrara, Ferrara ; 1 Department of Medical Sciences, University Piemonte Orien 2009;22(I):73-83

35. Han T, Abdel-Motal UM, Chang D, Sui J, Muvaffak A, Campbell J, et al. Human anti-CCR4 Minibody gene transfer for the treatment of cutaneous Tcell lymphoma. PLoS One. 2012;7(9):e44455.

36. Abdel-Motal UM, Harbison C, Han T, Pudney J, Anderson DJ, Zhu Q, et al. Prolonged expression of an anti-HIV-1 gp120 minibody to the female rhesus macaque lower genital tract by AAV gene transfer. Gene Ther. 2014; 21(9):802-10.

37. Van Wauwe JP, Goossens JG. The mitogenic activity of OKT3 and anti-Leu 4 monoclonal antibodies: a comparative study. Cell Immunol. 1983;77(1):23-9.

38. Chatenoud LFCLC, et al. In vivo cell activation following OKT3 administration.Pdf. Transplantation. 1990;49(4):697-702.

39. Malcolm SL, Smith EL, Bourne T, Shaw S. A humanised mouse model of cytokine release : comparison of CD3-speci fi c antibody fragments. J Immunol Methods. 2012;384(1-2):33-42.

40. Herold KC, Burton JB, Francois F, Poumian-Ruiz E, Glandt M, Bluestone JA. Activation of human T cells by FcR nonbinding anti-CD3 mAb, hOKT3??1(ala-ala). J Clin Invest. 2003;111(3):409-18.

41. Li L, van Nishio Junko MA, et al. Differential response of regulatory and conventional CD4+ lymphocytes to CD3 engagement: clues to a possible mechanism of anti-CD3 action? J Immunol. 2013;197(7):3694-704.

42. Chatenoud L. CD3-specific antibody-induced active tolerance: from bench to bedside. Nat Rev Immunol. 2003;3(2):123-32.

43. Besançon A, Baas M, Goncalves T, Valette F, Waldmann H, Chatenoud L, et al. The induction and maintenance of transplant tolerance engages both regulatory and anergic CD4+ T cells. Front Immunol. 2017;8(MAR):1-11.

44. Bluestone J, Mackay C, O'Shea J, Stockinger B. The functional plasticity of T cell subsets. Nat Rev Immunol. 2009;9(11):811-6.

45. Yang J, Fan $\mathrm{H}, \mathrm{Hao} J$, Ren $\mathrm{Y}, \mathrm{Chen} \mathrm{L}$, Li G, et al. Amelioration of acute graftversus-host disease by adoptive transfer of ex vivo expanded human cord blood CD4+CD25+ forkhead box protein $3+$ regulatory $T$ cells is associated with the polarization of Treg/Th17 balance in a mouse model. Transfusion. 2012;52(6):1333-47.

46. Sousa IG, do Almo MM, KCR S, MAG B, Andrade RV, Maranhão AQ, et al. MicroRNA expression profiles in human CD3+ T cells following stimulation with anti-human CD3 antibodies. BMC Res Notes. 2017:10(1):124.

47. Cretney E, Xin A, Shi W, Minnich M, Masson F, Miasari M, et al. The transcription factors Blimp-1 and IRF4 jointly control the differentiation and function of effector regulatory T cells. Nat Publ Gr. 2011;12(4):304-11.

48. Liu W, Putnam AL, Xu-yu Z, Szot GL, Lee MR, Zhu S, et al. CD127 expression inversely correlates with FoxP3 and suppressive function of human CD4 + T reg cells. J Exp Med. 2006:203(7):1701-11.

49. Shen LS, Wang J, Shen DF, Yuan XL, Dong P, Li MX, et al. CD4+CD25+ CD127low/- regulatory $T$ cells express Foxp3 and suppress effector $T$ cell proliferation and contribute to gastric cancers progression. Clin Immunol. 2009;131(1):109-18.

50. Saraiva M, Garra AO. The regulation of IL - 10 production by immune cells. Nat Rev Immunol. 2010;10(3):170-81.

51. Dummer CD, Carpio VN, Felipe L, Gonçalves S, Manfro RC, Veronese FV. FOXP3 + regulatory $T$ cells : from suppression of rejection to induction of renal allograft tolerance $i$. Transpl Immunol. 2012;26(1):1-10.

52. Long SA, Thorpe J, Herold KC, Ehlers M, Sanda S, Lim N, et al. Remodeling T cell compartments during anti-CD3 immunotherapy of type 1 diabetes. Cell Immunol. 2017;319:3-9.

53. Speiser DE, Utzschneider DT, Oberle SG, Münz C, Romero P, Zehn D. T cell differentiation in chronic infection and cancer: Functional adaptation or exhaustion?. Vol. 14, Nature Reviews Immunology. Nat Publ Group; 2014. p. 768-74.
54. Curran TA, Jalili RB, Farrokhi A, Ghahary A. IDO expressing fibroblasts promote the expansion of antigen specific regulatory $T$ cells. Immunobiology. 2014;219(1):17-24.

55. Curti A, Pandolfi S, Valzasina B, Aluigi M, Isidori A, Ferri E, et al. Modulation of tryptophan catabolism by human leukemic cells results in the conversion of. Blood. 2006;109:2871-8.

56. Ratajczak P, Janin A. Peffault de Larour R, Koch L, Roche B, Munn D, et al. IDO in human gut graft-versus-host disease. Biol Blood Marrow Transplant. 2012;18(1):150-5.

57. Babraham Institute. Barbraham bioinformatics, Cambridge. https://www. bioinformatics.babraham.ac.uk/projects/fastqc/

58. University of California Santa Cruz. USCS Genome Browser. http://genome. ucsc.edu/cgi-bin/hgGateway?db=hg19

59. Hoffmann S, Otto C, Kurtz S, Sharma CM, Khaitovich P, Vogel J, et al. Fast mapping of short sequences with mismatches, insertions and deletions using index structures. PLoS Comput Biol. 2009;5(9):1-10.

60. Li H, Handsaker B, Wysoker A, Fennell T, Ruan J, Homer N, et al. The sequence alignment/map format and SAMtools. Bioinformatics. 2009;25(16): 2078-9.

61. Anders S, Pyl PT, Huber W. HTSeq-A Python framework to work with highthroughput sequencing data. Bioinformatics. 2015;31(2):166-9.

62. Love Ml, Huber W, Anders S. Moderated estimation of fold change and dispersion for RNA-seq data with DESeq2. Genome Biol. 2014;15(12):1-21.

63. Mi H, Muruganujan A, Thomas PD. PANTHER in 2013: modeling the evolution of gene function, and other gene attributes, in the context of phylogenetic trees. Nucleic Acids Res. 2013:41(D1):377-86.

64. Chen EY, Tan CM, Kou Y, Duan Q, Wang Z, Meirelles GV, et al. Enrichr : interactive and collaborative HTML5 gene list enrichment analysis tool. 2013;

\section{Publisher's Note}

Springer Nature remains neutral with regard to jurisdictional claims in published maps and institutional affiliations.
Ready to submit your research? Choose BMC and benefit from:

- fast, convenient online submission

- thorough peer review by experienced researchers in your field

- rapid publication on acceptance

- support for research data, including large and complex data types

- gold Open Access which fosters wider collaboration and increased citations

- maximum visibility for your research: over $100 \mathrm{M}$ website views per year

At $\mathrm{BMC}$, research is always in progress.

Learn more biomedcentral.com/submissions 